\title{
Two agroinfection-compatible fluorescent protein-tagged infectious cDNA clones of papaya leaf distortion mosaic virus facilitate the tracking of virus infection
}

\author{
D. C. TUO, P. YAN, G. Y. ZHAO, X. Y. LI, P. ZHOU*, W. T. SHEN* \\ Key Laboratory of Biology and Genetic Resources of Tropical Crops, Ministry of Agriculture \& Institute of Tropical Bioscience \\ and Biotechnology, Chinese Academy of Tropical Agricultural Sciences, Haikou, P. R. China
}

Received July 21, 2017; accepted August 22, 2017

\begin{abstract}
Summary. - Papaya leaf distortion mosaic virus (PLDMV, the genus Potyvirus) is an emerging threat to papaya production. Here, agroinfection-compatible fluorescent protein-tagged PLDMV infectious cDNA clones driven by the Cauliflower mosaic virus 35 S promoter were successfully constructed using one-step Gibson assembly. The clones were directly transformed into Agrobacterium tumefaciens to prevent potential problems such as plasmid instability during propagation in Escherichia coli. Ninety-five percent of papaya seedlings infected with PLDMV-GFP or PLDMV-mCherry developed systemic symptoms typical of those caused by wild-type PLDMV. Green and mCherry red fluorescence was observed in leaves, stems, and roots of infected papaya plants. The fluorescent protein-tagged agroinfectious PLDMV cDNA clones were stable in papaya for more than 90 days and during six serial passages at 30-day intervals. The availability of these infectious clones will contribute to research on PLDMV-host interactions and can be applied in the papaya breeding program for PLDMV resistance.
\end{abstract}

Keywords: PLDMV; fluorescent protein-tagged; agroinfectious clones

The construction of full-length infectious cDNA clones of plant viruses is a key step in developing a reverse genetic system for RNA viruses. Plant virus infectious clones tagged with fluorescent proteins and non-fluorescent genes have been used as highly sensitive probes to monitor the replication and the cell-to-cell and systemic movement of viruses in plants (Pasin et al., 2014; Tilsner et al., 2010). Potyviruses are one of the largest and most economically important groups of plant viruses. Foreign genes have been added to the potyviral genome via a pentapeptide insertion at the N-terminus of P1 (Rajamäki et al., 2005) and two proteolytic sites between P1 and HCPro (Cui and Wang, 2016) or between the NIb and CP genes (Kelloniemi et al., 2006; Bedoya et al., 2012; Lee et al., 2011),

*Corresponding author. E-mail: zhoupeng@itbb.org.cn and dnaswt@hotmail.com; phone: +86-898-6890687.

Abbreviations: PLDMV = papaya leaf distortion mosaic virus; $\mathrm{PRSV}=$ papaya ringspot virus; GFP = green fluorescent protein; $\mathrm{mCherry}=\mathrm{mCherry}$ red fluorescent protein and these additions have not affected viral infectivity. To date, the complex process of viral infection and plant-virus-vector interactions have been studied using more than 13 in vitro- or in vivo-transcribed, fluorescently tagged potyviruses including potato virus A (Rajamäki et al., 2005, Kelloniemi et al., 2006), tobacco etch virus (Majer et al., 2013), potato virus Y (Matevz et al., 2015), plum pox virus (Lansac et al., 2005; Cui and Wang 2016), tobacco vein banding mosaic virus (Gao et al., 2012), clover yellow vein virus (Masuta et al., 2000), pepper mottle virus (Lee et al., 2011), tobacco vein mottling virus (Dietrich and Maiss , 2003), lettuce mosaic virus (German-Retana et al., 2003; Bordat et al., 2015), turnip mosaic virus (Beauchemin et al., 2005), soybean mosaic virus (Seo et al., 2009), zucchini yellow mosaic virus (Kang et al., 2016) and papaya ringspot virus (Tuo et al., 2017). Recently, the Antirrhinum majus MYBtype Rosea1 transcription factor, a non-fluorescent marker that activates anthocyanin accumulation in infected tissues, has been used to tag several potyviruses (Cordero et al., 2017; Bedoya et al., 2012). 
Papaya leaf distortion mosaic virus (PLDMV), a member of the genus Potyvirus in the family Potyviridae, was first reported from Okinawa Island of Japan in 1954 (Maoka et al., 1996). PLDMV infection causes mosaic symptoms and distortion of leaves, water-soaking streaks on stems and peti- oles, and ring spots on papaya fruits, similar to the symptoms caused by papaya ringspot virus (PRSV, potyvirus), which is the most widespread and destructive disease affecting papaya (Bau et al., 2008). An isolate of PLDMV-DF from China was recently identified in the commercialized PRSV-resistant

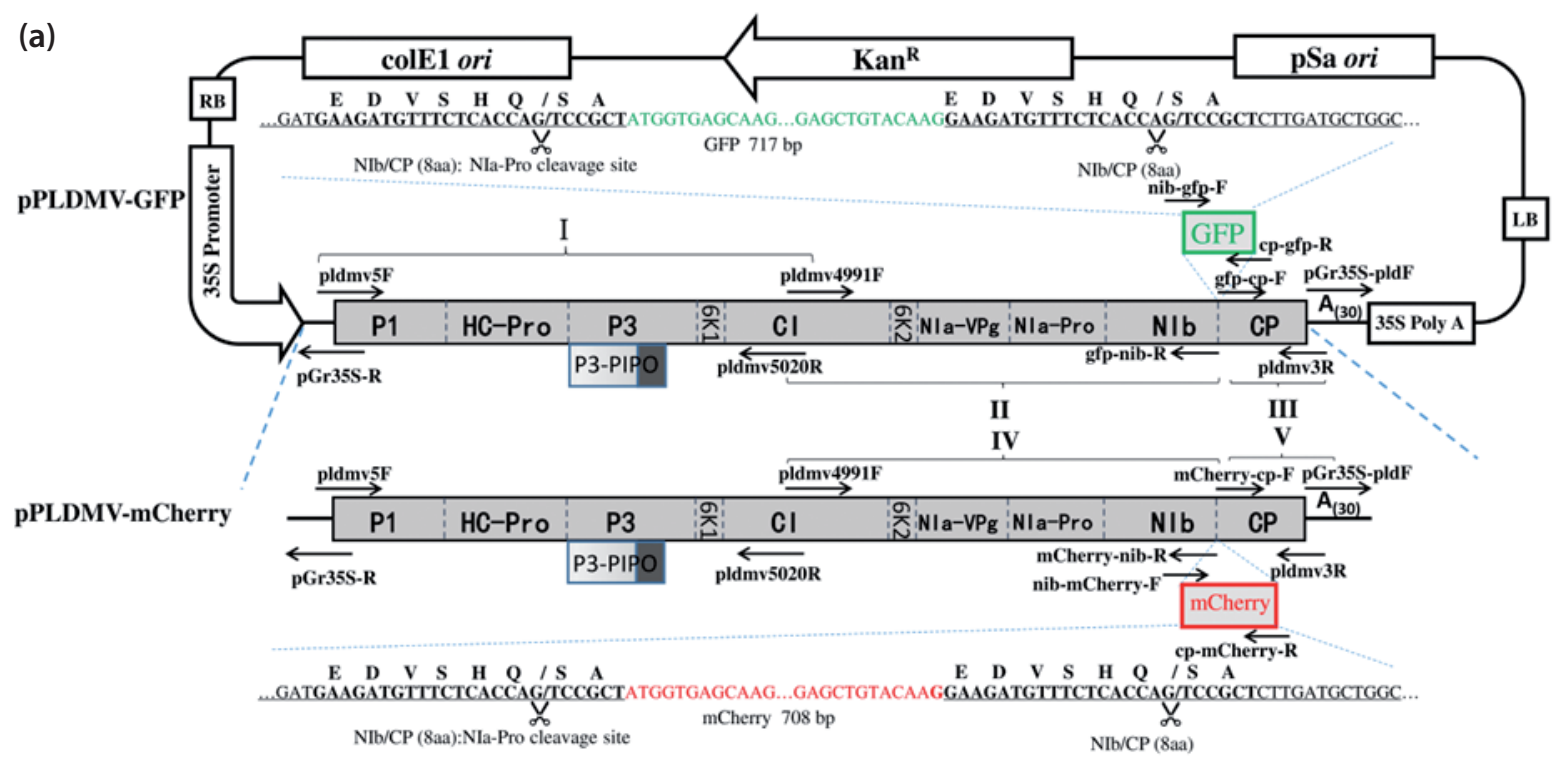

(b)

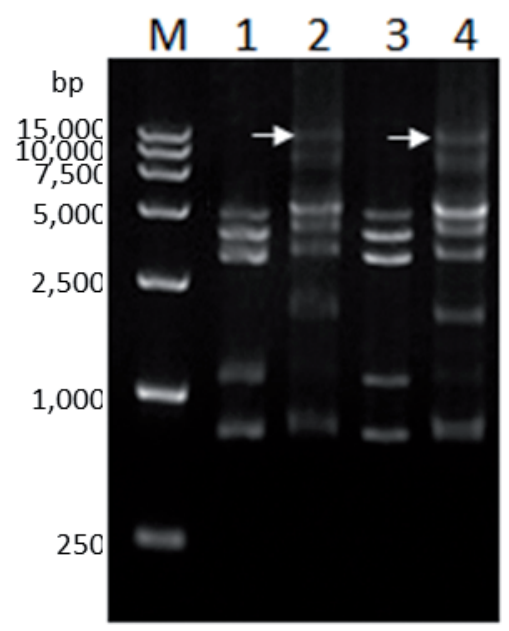

Fig. 1

Strategy to construct fluorescent protein-tagged PLDMV agroinfectious cDNA clones using Gibson assembly

(a) Schematic representation of recombinant PLDMV clones: PLDMV-GFP and PLDMV-mCherry. GFP or mCherry fragment was assembled into NIb/ CP junction of PLDMV genome with three PLDMV fragments (I, II, and III, or I, IV, and V) and pGreenII-35S PCR fragment to produce pPLDMV-GFP or PLDMV-mCherry vector. Adjacent sequences of NIb and CP are underlined. Octapeptide recognized by NIa protease is shown in large bold letters. Scissors indicate cleavage site of NIa. Artificially introduced NIa-Pro cleavage sites are marked in blue. White rectangles and arrows indicate elements on backbone of pGreenII-35S vector. Genome organization of PLDMV is indicated by grey rectangles. Green and red rectangles represent GFP and $m$ Cherry, respectively, and their nucleotide sequences are shown in italics. Black arrows indicate primers used to construct recombinant PLDMV clones (Table S1). (b) Agarose gel electrophoresis of Gibson assembly reaction products. Five PCR amplification products (fragment I, 5045 bp; II, 4091 bp; III, 1155 bp; GFP, 741 bp; pGreenII-35S, 3235 bp) (lane 1) used to create plasmid pPLDMV-GFP and recombination product (lane 2) obtained after Gibson assembly; five PCR amplification products (fragment I, 5045 bp; IV, 4091 bp; V, 1154 bp; mCherry, 733 bp; pGreenII-35S, 3235 bp) (lane 3) used to create the plasmid pPLDMV-mCherry and recombination product (lane 4) obtained after Gibson assembly. Arrows indicate position of recombination products obtained after Gibson assembly. M, DNA ladder. 
transgenic papaya (Tuo et al., 2013) and co-infected with PRSV (Shen et al., 2014). PLDMV is becoming an emerging threat to papaya production in China (Bau et al., 2008; Shen et al., 2014). The PLDMV-DF isolate (GenBank Acc. No. JX974555) has a single-stranded positive-sense RNA genome of 10,153 nucleotides (nt) excluding the poly-A tail. Like other potyviruses, PLDMV-DF has a genome that encodes a long open reading frame (ORF) and another short ORF that results from slippage of the RNA polymerase at the P3 cistron (Tuo et al., 2013). The polyproteins are proteolytically processed by three viral protease domains into 11 mature viral proteins (P1, HC-Pro, P3, P3N-PIPO, 6K1, CI, 6K2, VPg, NIa-Pro, NIb, and CP). Phylogenetic analyses suggest that PLDMV-DF is most closely related to an isolate from Japan (Maoka et al., 1996; Tuo et al., 2013). Based on a previous study, the full-length cDNA of PLDMV is unstable during propagation in E. coli and that $\mathrm{P} 3$ and CI are the main regions of instability (Tuo et al., 2015; 2017). To overcome this problem, a stable in vitro-transcribed infectious PLDMV clone was produced by inserting an intron into (a)

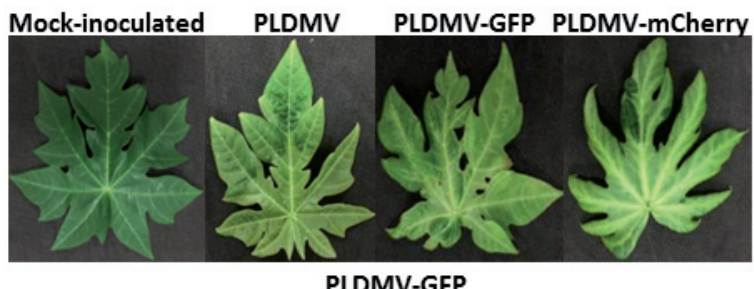

(b)
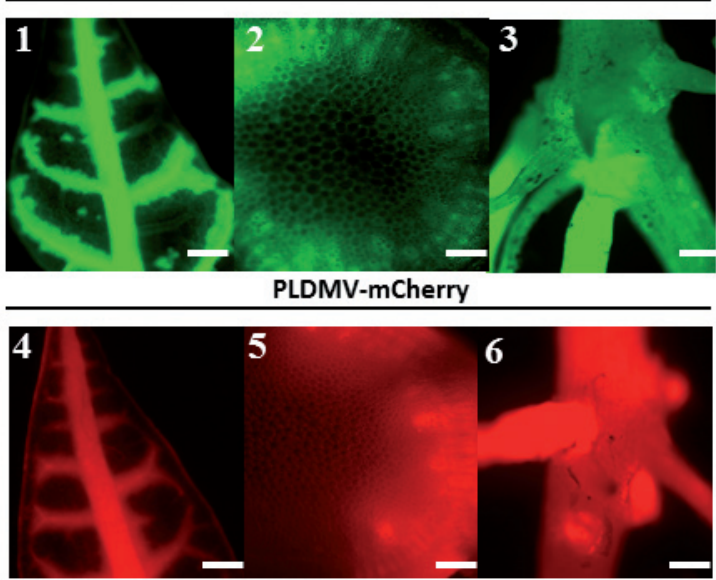

(d)

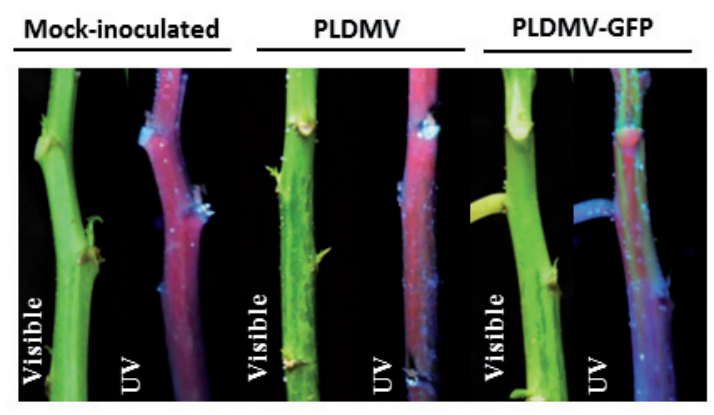

(c)

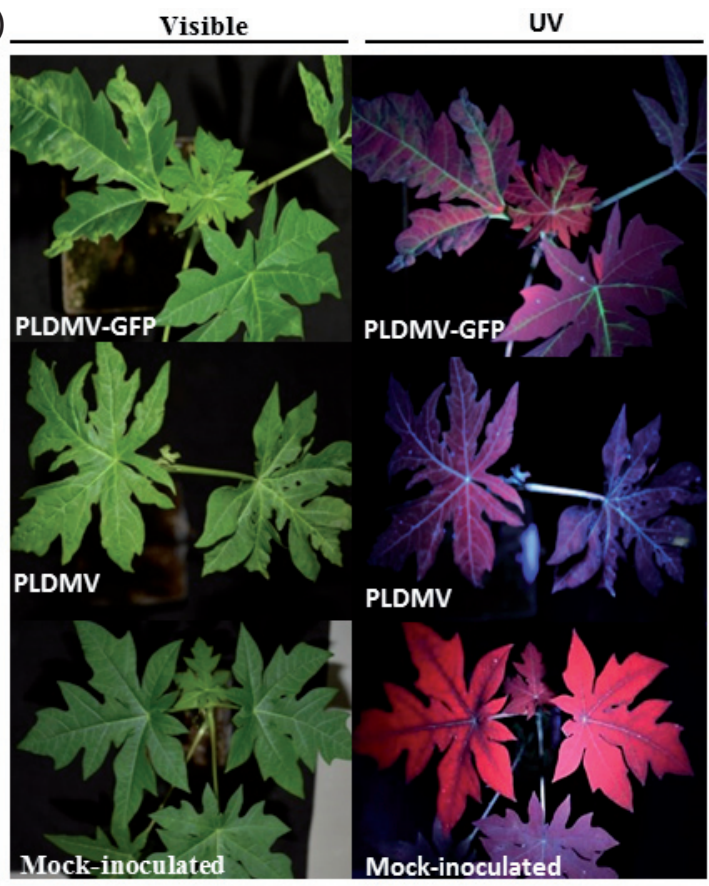

(e)
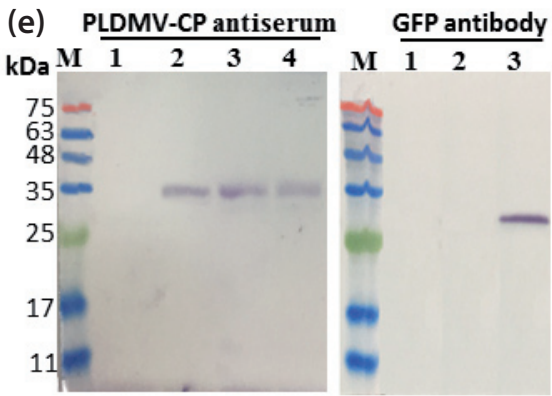

RFP antibody

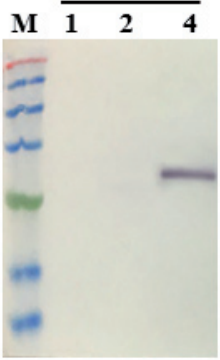

Fig. 2

Determination of fluorescence signals after agroinoculation with PLDMV-GFP, or PLDMV-mCherry infectious cDNA clones (a) Symptoms induced by PLDMV (Tuo et al., 2017), PLDMV-GFP, and PLDMV-mCherry infectious cDNA clones at 90 days post inoculation (dpi). (b) Detection of GFP and mCherry expression under epifluorescence microscope at $10 \mathrm{dpi}$ in papaya leaves (1, green fluorescence; 4 , red fluorescence), stem cross sections (2, GFP fluorescence; 5, mCherry red fluorescence), and roots (3, green fluorescence; 6 , red fluorescence) of plants systemically infected with PLDMV, PLDMV-GFP, or PLDMV-mCherry, respectively. Bars $=20 \mu \mathrm{m}$. (c) GFP fluorescence under ultraviolet light in papaya plants infected with PLDMV-GFP at 30 dpi. (d) Water-soaking streaks on stems induced by PLDMV and PLDMV-GFP, and GFP fluorescence under ultraviolet light on stems infected with PLDMV-GFP at 30 dpi. (e) Western blot analysis of PLDMV (lane 2), PLDMV-GFP (lane 3), or PLDMV-mCherry (lane 4) infection in papaya plants using CP antiserum, GFP antibody, and RFP antibody, respectively. Mock-inoculated plants (lane 1) were used as negative control. M, prestained protein ladder. 
the unstable $\mathrm{P} 3$ region (Tuo et al., 2015). However, in vitro RNA transcription is time-consuming and inconvenient. Recently, a new cloning strategy based on one-step Gibson assembly and direct $A$. tumefaciens transformation was developed to generate stable infectious clones of PLDMV, which prevent potential problems such as plasmid instability during propagation in E. coli (Tuo et al., 2017). In this study, we developed green fluorescent protein (GFP) and mCherry red fluorescent protein (mCherry)-tagged agroinfectioncompatible cDNA clones using this new method for further studies on PLDMV-host interactions by in vivo tracking of the virus inside papaya plants.

To develop the GFP- or mCherry-tagged recombinant infectious PLDMV clones pPLDMV-GFP and pPLDMVmCherry, GFP and mCherry coding fragments were amplified from the vector $\mathrm{pVPH}-\mathrm{GFP} / / \mathrm{mCherry}$ (Cui and Wang, 2016). Then, each fragment was assembled into the NIb/CP junction of PLDMV genome with three PLDMV fragments (I, II, and III or I, IV and V) and the mini-binary vector pGreenII-35S PCR fragment (Hellens et al., 2000) by Gibson assembly (Fig. 1a) (Gibson et al., 2009). All overlapping primer pairs shared 25-36 homologous bases at each end
(Table S1). The synthesized first-strand cDNAs from total RNA of papaya leaves infected with PLDMV-DF were used as the template to amplify the PLDMV fragments (Tuo et al., 2015). The PCR amplification reactions were performed with Phusion ${ }^{\circledast}$ High-Fidelity DNA polymerase (New England BioLabs; NEB, USA) and PCR products were purified with the MiniBEST agarose gel DNA extraction kit (TaKaRa, Japan). The purified PCR products were assembled according to the instructions in the manual of the Gibson Assembly Cloning master mix (NEB). Briefly, 100 ng each purified PCR fragment and $5 \mu \mathrm{l} 2 \times$ Gibson mix (NEB) was incubated at $50^{\circ} \mathrm{C}$ for $1 \mathrm{~h}$. Agarose gel electrophoresis analysis confirmed the high efficiency of the Gibson assembly in vitro recombination reaction and revealed the high-molecular-weight fragments corresponding to pPLDMV-GFP and PPLDMVmCherry obtained by the Gibson assembly reaction (Fig. 1b). Then the Gibson assembly reaction products were directly transformed into A. tumefaciens strain C58C1, respectively (Tuo et al., 2017). Sequencing of the PCR products from $A$. tumefaciens transformants confirmed that the full-length viral sequences in pPLDMV-GFP and pPLDMV-mCherry were identical to that of the PLDMV-DF isolate, and that

(a)
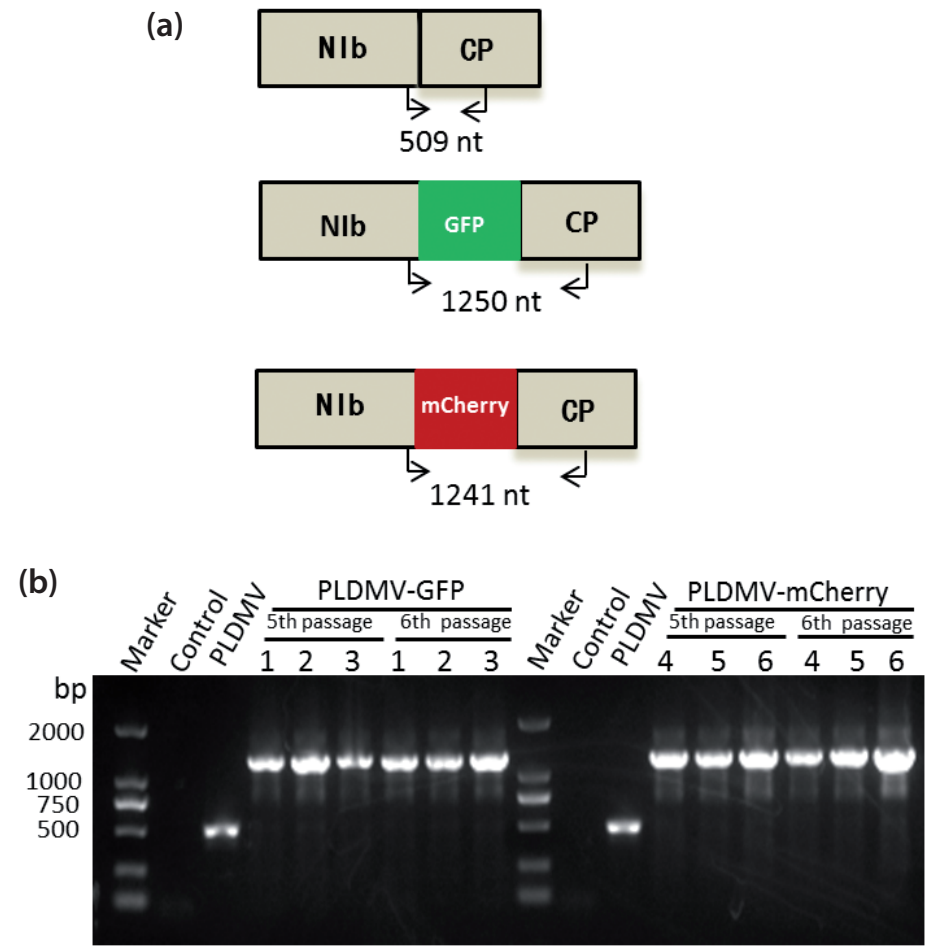

Fig. 3

Stability analysis of PLDMV-GFP and PLDMV-mCherry through serial passage in systemically infected leaves of papaya plants (a) Schematic map of NIb/CP, NIb/GFP/CP, and NIb/mCherry /CP regions in PLDMV genome. Arrows indicate region amplified with primers flanking GFP and mCherry cistron in PLDMV genome. RT-PCR yields 509-, 1250-, and 1241-bp products from PLDMV-, PLDMV-GFP- and PLDMV-mCherryinfected papaya plants, respectively. (b) RT-PCR amplification profile from papaya plants infected with PLDMV-GFP and PLDMV-mCherry at 30 dpi of $5^{\text {th }}$ serial passage (lanes 1-3) and $6^{\text {th }}$ serial passage (lanes 4-6). Buffer-inoculated and PLDMV-infected papaya plants were used as controls. 
no spontaneous mutations, deletions, or rearrangements of viral fragments had occurred. The sequencing results also confirmed that GFP or mCherry was introduced correctly between the NIb and CP cistrons flanked by original and artificial NIa-Pro cleavage peptides.

Two leaves of each of 20 papaya plants were agroinoculated with each $A$. tumefaciens transformant harboring the plasmid pPLDMV (Tuo et al., 2017), pPLDMV-GFP, or pPLDMV-mCherry. Ninety-five percent of the agroinoculated papaya seedlings developed systemic mosaic symptoms on leaves and water-soaking symptoms on the stem, with the streaks indistinguishable from the typical symptoms caused by wild-type PLDMV at 30 days post inoculation (dpi). Insertion of GFP or mCherry with octapeptide cleavage sequences did not affect the infection efficiency or symptom phenotypes of PLDMV in papaya (Fig. 2a). Moreover, from 10 dpi downwards, GFP or mCherry fluorescence was detected in different parts of systematically infected papaya plants (leaves, stem, and roots) under an epifluorescence microscope (Zeiss, Jena, Germany) (Fig. 2b). Using these analyses, we were able to track the movement of PLDMVGFP and PLDMV- mCherry during the source-to-sink transportation of photoassimilates through the vasculatureassociated tissues and phloem (Hipper et al., 2013). When symptomatic plants infected pPLDMV-GFP were illuminated with ultraviolet light, strong green fluorescence was observed in leaves and stem at $20 \mathrm{dpi}$ and was still detectable at $90 \mathrm{dpi}$ (Fig. 2c,d). Using western blot analyses, we were able to detect the $27 \mathrm{kDa}$ GFP or mCherry from total proteins extracted from leaves of papaya infected with pPLDMV-GFP or pPLDMV-mCherry (Fig. 2e). These results confirmed that the inserted homologous artificial NIa-Pro cleavage sites at the C-terminus of GFP or mCherry released GFP or mCherry from the $\mathrm{CP}$ as expected.

The stability of pPLDMV-GFP and pPLDMV-mCherry after infection was monitored during six serial passages in papaya plants by mechanical inoculation at 30-day intervals. In RT-PCR analyses of total RNA from passages 1 through 6 from papaya plants infected with pPLDMV-GFP or pPLDMV-mCherry, the intact GFP or mCherry were detected as products of the expected size. The primers used in these analyses were pldmv9000F: GAAATGTGTGCAAACG ATTTTAACG and pldmv9508R: CCATTCTCAATACA CCAAACCATT, which flanked the GFP or mCherry cistron at the 3 ' end of the NIb and at the 5 ' end of the CP (Fig. $3 \mathrm{a}$ ). After six passages of the viral clones in papaya plants, the infectivity of the viral clones remained unchanged and GFP or mCherry fluorescence was detected in the systematically infected papaya plants (Fig. 3b).

Taken together, these results illustrate that stable fluorescent protein-tagged agroinfectious cDNA clones were successfully constructed by one-step Gibson assembly followed by direct transformation into $A$. tumefaciens without plasmid propagation in E. coli. These GFP and mCherry-tagged PLDMVs are certainly useful tools to facilitate research on PLDMV-host interactions and evaluation of PLDMV resistance in papaya breeding.

Acknowledgments. This work was supported by Innovative Research Team of the Natural Science Foundation of Hainan Province, China (grant No. 2018CXTD343). We thank Dr. Aiming Wang (London Research and Development Centre, Agriculture and AgriFood Canada) for his linguistic assistance during the preparation of this manuscript.

Supplementary information is available in the online version of the paper.

\section{References}

Bau HJ, Kung YJ, Raja JA, Chan SJ, Chen KC, Chen YK, Wu HW, Yeh SD (2008): Potential threat of a new pathotype of Papaya leaf distortion mosaic virus infecting transgenic papaya resistant to Papaya ringspot virus. Phytopathology 2008, 98, 848-856. https://doi.org/10.1094/PHYTO-98$\underline{7-0848}$

Beauchemin C, Bougie V, Laliberté JF (2005): Simultaneous production of two foreign proteins from a polyvirus-based vector. Virus Res. 112, 1-8. https://doi.org/10.1016/j. virusres.2005.03.001

Bedoya LC, Martínez F, Orzáez D, Daròs JA (2012): Visual tracking of plant virus infection and movement using a reporter MYB transcription factor that activates anthocyanin biosynthesis. Plant Physiol. 158, 1130-1138. https://doi. org/10.1104/pp.111.192922

Bordat A, Houvenaghel MC, German-Retana (2015): Gibson assembly: an easy way to clone potyviral full-length infectious cDNA clones expressing an ectopic VPg. Virol. J. 12, 89. https://doi.org/10.1186/s12985-015-0315-3

Cordero T, Mohamed MA, López-Moya JJ, Daròs JA (2017): A recombinant Potato virus Y infectious clone tagged with the Rosea1 visual marker (PVY-Ros1) facilitates the analysis of viral infectivity and allows the production of large amounts of anthocyanins in plants. Front. Microbiol. 8, 611. https://doi.org/10.3389/fmicb.2017.00611

Cui $\mathrm{H}$, Wang A (2016): Plum pox virus $6 \mathrm{~K} 1$ protein is required for viral replication and targets the viral replication complex at the early stage of infection. J. Virol. 90, 5119-5131. https://doi.org/10.1128/JVI.00024-16

Dietrich C, Maiss E (2003): Fluorescent labelling reveals spatial separation of potyvirus populations in mixed infected Nicotiana benthamiana plants. J. Gen. Virol. 84, 28712876. https://doi.org/10.1099/vir.0.19245-0

Gao R, Tian YP, Wang J, Yin X, Li X.D, Valkonen JP (2012): Construction of an infectious cDNA clone and gene expression vector of Tobacco vein banding mosaic virus (genus Potyvirus). Virus Res. 169, 276-281. https://doi. org/10.1016/j.virusres.2012.07.010

German-Retana S, Redondo E, Tavert-Roudet G, Le Gall O, Candresse T (2003): Introduction of a NIa proteinase cleavage 
site between the reporter gene and HC-Pro only partially restores the biological properties of GUS- or GFP-tagged LMV. Virus Res. 98, 151-162. https://doi.org/10.1016/j. virusres.2003.09.005

Gibson DG, Young L, Chuang RY, Venter, JC, Hutchison CA. 3rd, Smith HO (2009): Enzymatic assembly of DNA molecules up to several hundred kilobases. Nat. Methods 6, 343-345. https://doi.org/10.1038/nmeth.1318

Hellens R, Mullineaux P, Klee H (2000): Technical focus: a guide to Agrobacterium binary Ti vectors. Trends Plant Sci. 5,446451. https://doi.org/10.1016/S1360-1385(00)01740-4

Hipper C, Brault V, Ziegler-Graff V, Revers F (2013): Viral and cellular factors involved in Phloem transport of plant viruses. Front. Plant Sci. 4,154. https://doi.org/10.3389/ fpls.2013.00154

Kang M, Seo J.K, Choi H, Cho HS, Kim KH (2016): Establishment of a simple and rapid gene delivery system for cucurbits by using engineered of Zucchini yellow mosaic virus. Plant Pathol. J. 32, 70-76. https://doi.org/10.5423/PPJ. NT.08.2015.0173

Kelloniemi J, Mäkinen K, Valkonen JP (2006): A potyvirus-based gene vector allows producing active human S-COMT and animal GFP, but not human sorcin, in vector-infected plants. Biochimie 88, 505-513. https://doi.org/10.1016/j. $\underline{\text { biochi. } 2005.10 .010}$

Lansac M, Eyquard JP, Salvador B, Garcia JA, Le Gall O, Decroocq V, Schurdi-Levraud Escalettes V (2005): Application of GFP-tagged Plum pox virus to study Prunus-PPV interactions at the whole plant and cellular levels. J. Virol. Methods 129, 125-133. https://doi.org/10.1016/j. jviromet.2005.05.016

Lee MY, Song YS, Ryu KH (2011): Development of infectious transcripts from full-length and GFP-tagged cDNA clones of Pepper mottle virus and stable systemic expression of GFP in tobacco and pepper. Virus Res. 155, 487-494. https:// doi.org/10.1016/j.virusres.2010.12.004

Majer E, Daròs JA, Zwart MP (2013): Stability and fitness impact of the visually discernible Roseal marker in the Tobacco etch virus genome.Viruses 5, 2153-2168. https://doi. org/10.3390/v5092153

Maoka T, Kashiwazaki S, Tsuda S, Usugi T, Hibino H (1996): Nucleotide sequence of the capsid protein gene of papaya leafdistortion mosaic potyvirus. Arch. Virol. 141, 197-204. https://doi.org/10.1007/BF01718601
Masuta C, Yamana T, Tacahashi Y, Uyeda I, Sato M, Ueda S, Matsumura T (2000): Development of clover yellow vein virus as an efficient, stable gene-expression system for legume species. Plant J. 23,539-546. https://doi. org/10.1046/j.1365-313x.2000.00795.x

Matevz R, Florence F, Michel T, Ion GA, Agnès D, Laurent G, Maja K, David D, Kristina G, Emmanuel J, Maja R (2015): Fluorescently tagged potato virus Y: A Versatile tool for functional analysis of plant-virus interactions. Mol. Plant Microbe. Interact. 28, 739-750. https://doi.org/10.1094/ MPMI-07-14-0218-TA

Pasin F, Kulasekaran S, Natale P, Simón-Mateo C, García JA (2014): Rapid fluorescent reporter quantification by leaf disc analysis and its application in plant-virus studies. Plant Methods 10, 22. https://doi.org/10.1186/17464811-10-22

Rajamäki ML, Kelloniemi J, Alminaite A, Kekarainen T, Rabenstein F, Valkonen JP (2005): A novel insertion site inside the potyvirus P1 cistron allows expression of heterologous proteins and suggests some P1 functions. Virology 342, 88-101. https://doi.org/10.1016/j.virol.2005.07.019

Seo JK, Lee HG, Kim KH (2009): Systemic gene delivery into soybean by simple rub-inoculation with plasmid DNA of a Soybean mosaic virus-based vector. Arch. Virol. 154, 87-99. https://doi.org/10.1007/s00705-008-0286-4

Shen W, Tuo D, Yang Y, Yan P, Li X, Zhou P (2014): First report of mixed infection of Papaya ringspot virus and Papaya leaf distortion mosaic virus on Carica papaya L. J. Plant Path. 96,121.

Tilsner J, Oparka KJ (2010): Tracking the green invaders: advances in imaging virus infection in plants. Biochem J. 430, 21-37. https://doi.org/10.1042/BJ20100372

Tuo D, Shen W, Yan P, Li Ch, Gao L, Li X, Li H, Zhou P (2013): Complete genome sequence of an isolate of papaya leaf distortion mosaic virus from commercialized PRSVresistant transgenic papaya in China. Acta Virol. 57, 452-455. https://doi.org/10.4149/av $2013 \quad 04 \quad 452$

Tuo D, Shen W, Yan P, Li X, Zhou P (2015): Rapid construction of stable infectious full-length cDNA clone of papaya leaf distortion mosaic virus using in-fusion cloning. Viruses 7, 6241-6250. https://doi.org/10.3390/v7122935

Tuo D, Fu L, Shen W, Li X, Zhou P, Yan P (2017): Generation of stable infectious clones of plant viruses by using Rhizobium radiobacter for both cloning and inoculation. Virology 510, 99-103. https://doi.org/10.1016/j.virol.2017.07.012 


\title{
Supplementary information
}

\section{Two agroinfection-compatible fluorescent protein-tagged infectious cDNA clones of papaya leaf distortion mosaic virus facilitate the tracking of virus infection}

\author{
D. C.TUO, P. YAN, G. Y. ZHAO, X. Y. LI, P. ZHOU*, W. T. SHEN*
}

Key Laboratory of Biology and Genetic Resources of Tropical Crops, Ministry of Agriculture \& Institute of Tropical Bioscience and Biotechnology, Chinese Academy of Tropical Agricultural Sciences, Haikou, P. R. China

Received July 21, 2017; accepted August 22, 2017

Table S1. Primers used for amplification of various gene fragments

\begin{tabular}{|c|c|c|}
\hline Primer & Sequence (5'-3') & PCR product \\
\hline \multirow{2}{*}{ pGr35S-pldF } & GGGAAAAAAAAAAAAAAAAAAAAAAAAAAAAAATCGGTACGCTGAAATCA & \multirow{3}{*}{ pGreenII-35S fragment } \\
\hline & CCAGTCTC & \\
\hline pGr35S-R & СCTCTCCAAATGAAATGAACTTCCT & \\
\hline pldmv5F & AGGAAGTTCATTTCATTTGGAGAGGAAAAATATAAAAACTCAACAAAACTTATGC & \multirow{2}{*}{ fragment I } \\
\hline pldmv5020R & ACTATATCGGTCGAACCAATTTTCATGG & \\
\hline pldmv4991F & CACCATGAAAATTGGTTCGACCGATAT & \multirow{2}{*}{ fragment II } \\
\hline gfp-nib-R & CCTTGCTCACCATAGCGGACTGGTGAGAAACATCTTCATC & \\
\hline gfp-cp-F & CGAGCTGTACAAGGAAGATGTTTCTCACCAGTCCGCTCTT & \multirow{2}{*}{ fragment III } \\
\hline pldmv3R & CGATTTTTTTTTTTTTTTTTTTTTTTTTTTTTTCCCTCCTTGCTTAGTCTGAAGTTCC & \\
\hline pldmv4991F & CACCATGAAAATTGGTTCGACCGATAT & \multirow{2}{*}{ fragment IV } \\
\hline mCherry-nib-R & CCTTGCTCACCATAGCGGACTGGTGAGAAACATCTTCA & \\
\hline mCherry-cp-F & GAGCTGTACAAGGAAGATGTTTCTCACCAGTCCGCTC & \multirow{2}{*}{ fragment $\mathrm{V}$} \\
\hline pldmv3R & CGATTTTTTTTTTTTTTTTTTTTTTTTTTTTTTCCCTCCTTGCTTAGTCTGAAGTTCC & \\
\hline nib-gfp-F & CACCAGTCCGCTATGGTGAGCAAGGGCGAGGAGCTGT & \multirow{2}{*}{ GFP } \\
\hline cp-gfp-R & AGAAACATCTTCCTTGTACAGCTCGTCCATGCCGAGAGT & \\
\hline nib-mCherry-F & CACCAGTCCGCTATGGTGAGCAAGGGCGAGGAGGAT & \multirow{2}{*}{ mCherry } \\
\hline cp-mCherry-R & GAGAAACATCTTCCTTGTACAGCTCGTCCATGCCGC & \\
\hline
\end{tabular}

All overlapping homologous bases are underlined. 